\title{
Posterior Urethral Obstruction: COPUM
}

\section{Paddy Dewan}

Wee Kids Urology Research Unit Melbourne, Victoria

Australia
Correspondence to:

Professor Paddy Dewan

Wee Kids Urology Research Unit Melbourne, Victoria

Australia.

E-mail:paddy@paddydewan.com

\section{w w w. b je nd o. or g}

Posterior urethral obstruction, like many conditions in Paediatric Urology, is simplified in any description that discusses its treatment. In reality, the changes in the urethra, bladder, ureters and kidneys are protean, and there is a spectrum of both the anatomical lesion and the clinical presentation.

The important facts that affect interpretation and management of these boys are:

1. The posterior urethral anomaly is a membrane with a posterior defect, with paramedian folds back to the crista, which would best be known as COPUM.

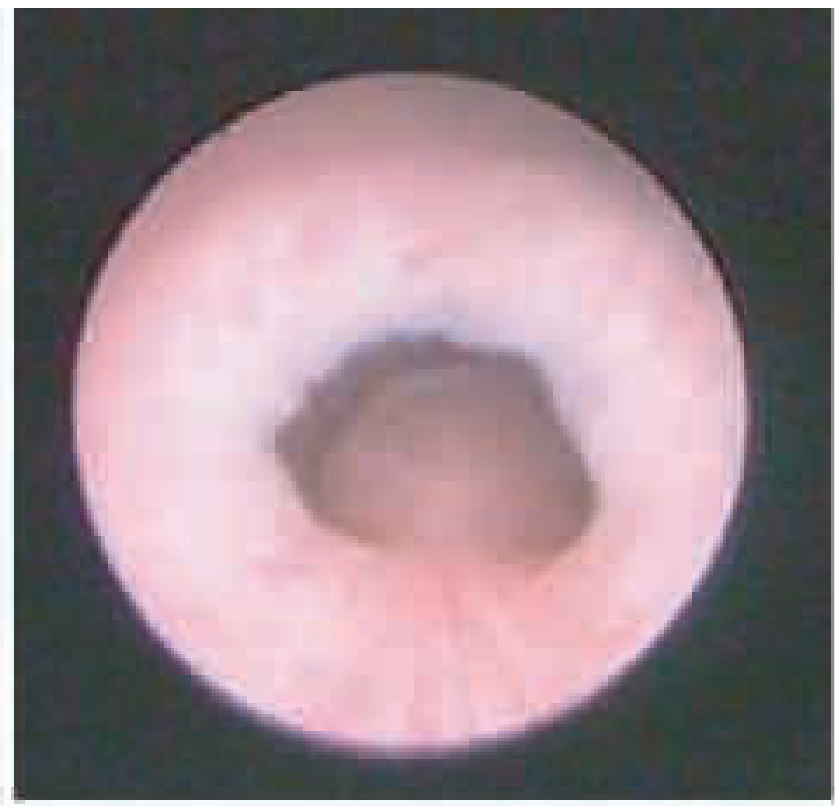

Figure 1: COPUM

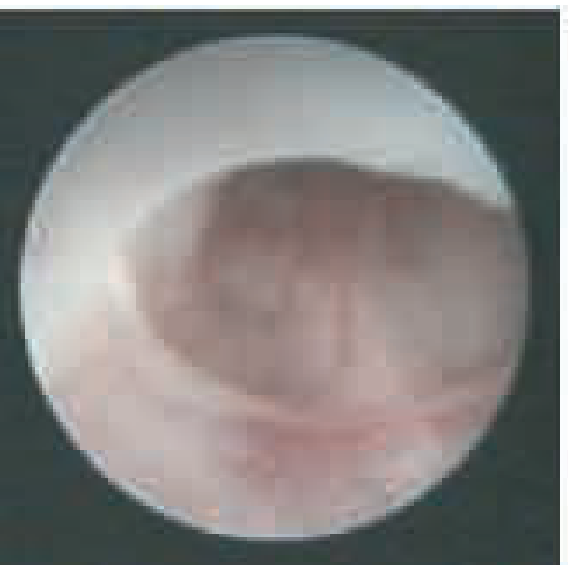

Figure 2: Minimal COPUM

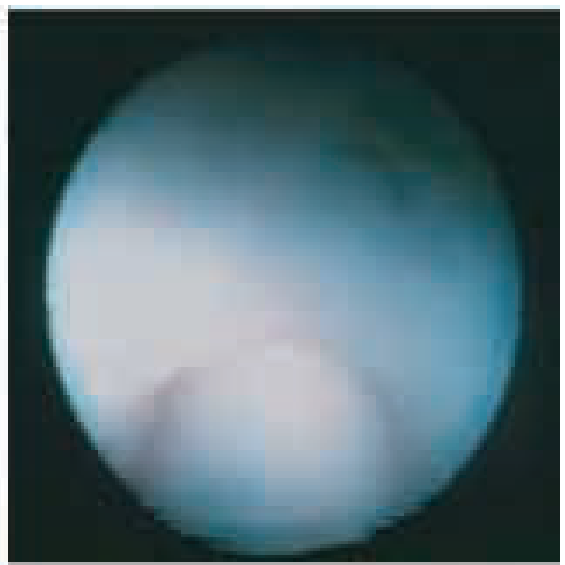

Figure 3: COPUM wide tight 
2. Passage of a catheter will reduce the degree of obstruction in many cases.

3. The top end of the external sphincter is above the level of the obstruction; the external sphincter is tube of muscle.

4. Bladder and upper tract changes do not always directly correlate with the degree of narrowing in the posterior urethra. A significant luminal narrowing may not be associated with adverse renal and bladder changes.

5. The degree of abnormality in the posterior urethra ranges from a minor indentation to severe obstruction, which is variable expression of the same embryopathy.

6. Bulbar urethral lesions are not in the posterior urethra, and are either a prolapsed COPUM (identified by the attachments to the verumontanum), the distal end of the external sphincter, or a fibrous narrowing (without veru connections), and best know as Cobb's Collar.

7. Ablating the obstruction may be only a minor contribution to the management of a complex patient.

These conclusions are based on extensive review of video recorded endoscopies and an extensive, and detailed, review of the many hundreds of papers written on the subject of posterior urethral obstruction ${ }^{1-8}$.

Obstruction of the posterior urethra was first described in 1717 by Morgagni, followed by a subsequent description by Langenbeck in 1802 in his monograph on stone disease ${ }^{9-10}$. Velpeau, in 1832, coined the term 'valves' because folds in the posterior urethra resembled cardiac valves when viewed in post-mortem dissections ${ }^{11}$.

Over the following 85 years, there were a total of 27 reports in the literature on 'valves', including detailed descriptions and illustrations of the posterior urethra at dissection. Early authors such as Budd in 1840 and Bednar in 1847 found the lesions fold-like and resemble the valve in a vein ${ }^{12-13}$. Not all authors agreed; Godart likened the lesion to a pigeon's nest and Jarjavay, to iris of an eye $\mathrm{e}^{14-15}$. Lederer provided two views of the autopsy specimen of an 11-year-old patient, concluding the abnormality to be a 'semicircular diaphragmatic obstruction below the verumontanum. ${ }^{16}$ Lowsley in 1914 found 'the entire structure is more or less dome shaped, make the term "diaphragm" more appropriate in referring to this anomaly ${ }^{17}$. Over 60 structures in the human body have been called valves, however not all have the cardinal feature of a valve which allows flow in one direction and impede flow in the opposite ${ }^{18}$. Velpeau and Budd while making the morphological description, certainly did not suggest any specific physiological intent of these lesions to prevent backflow of urine, nevertheless the term 'valves' has become entrenched in urological literature.
The seminal paper of Hugh Hampton Young was first read at the June 1919 meeting of the association of GenitoUrinary surgeons, in Atlantic City on behalf of Hugh Hampton Young and his co-authors William A Frontz and John C Baldwin. The manuscript reported a retrospective study of 12 cases treated at John Hopkins Hospital, Baltimore, reviewed the literature, and provided a six-part classification of posterior urethral obstruction. The 76 pages include a description of the endoscopic diagnosis of urethral "valves", mention the development a transurethral "punch" for treating the obstruction, and record the early use of the cystogram.

There are two major components to the 1919 paper; the first is the presentation of the 12 cases, all of which are described in great detail in the text and in Table 4. The cases ranged in age from 11 days to 42 years, with only five being of 12 months old or less. Importantly, only three of the 12 cases had been cystoscoped, and these three patients were 17, 26 and 42 years, one of who had previous venereal infection. In the classification table (Table 1), five were described as Type I valves, one as Type II and three were thought to be Type III. The three types were further subdivided, with three subtypes of Type I, one form of Type II, and two variants of the Type III lesions. Within the Type III group, one variant was thought to consist of a perforated membrane below the verumontanum, without attachment to the verumontanum, the other was thought to be above. Three of the 12 cases were not specifically classified thus a six-part classification was based on nine cases, three of which had only had finger palpation of the lesion. It is also interesting to note that the subtypes presented by Young et al., in the 1919 paper, differ from that published in the 1929 paper, and that the perforation of the Type III lesions below the verumontanum were considered either posterior (1919) or central (1929) $)^{19-20}$.

Detailed analysis of the cases, using the description in the text and Table 4, and in light of recent observations, one could suggest that Type Ia and Type Ib are iatrogenic modifications of a congenital posterior urethral obstruction for which there are attachments to the verumontanum. It should be noted that most of Young's Type I cases were thought to have two valves meeting in the midline, but not fused. 
Type II and Type III above the verumontanum, do not exist, and Type III obstruction below the verumontanum, without the attachment to the verumontanum, with a central defect, is probably a remnant of the urogenital diaphragm - if fibrous. This lesion is probably the same as those called Cobb's Collar, Moormann's Ring, or Congenital Stricture.

The second part of the paper is a review of the literature: 24 authors were credited with making case comments or presentations related to posterior urethral obstruction up to 1919, according to Young et al, whereas 26 were retrieved by the Hinman and Kutzmann paper for the same period; in total, five were included in the classification in one of these two studies but not the other. Three other cases have since been identified to have been published before 1919, from other sources; the lack of access to Medline and computers would easily explain the discrepancies. As occurred for the 12 cases, the extensive literature review does not indicate which of the historical cases reviewed were assigned to each part of the classification, thus precluding an accurate critical analysis. Critique is also hampered because only 20 of the listed literature cases were included in classification Table 1, and the number of cases in Table 5 (23 cases) differs from that in the case-description text (24 cases).

Of note, Iverson's case was included as a 15-year-old in the Table 5, was 85 years of age, as stated in the text, verified by reviewing Iverson's paper. Given the recent reinterpretation of the pathophysiology of VUR, because of lesions learnt form fetal studies, it is interesting to reflect on the age of the patients on which the classification of posterior urethral valve is based.

Young made two comments worth highlighting, particularly because they had not been substantiated by detail study of endoscopic recording. The first was that "cystoscopy furnishes little information regarding the type of urethral anomaly", which most would now find rather contentious, and "little or no difficulty is encountered in passing a catheter, but the ease of the instrumentation is by no means an index of the degree of obstruction".

An additional insight that refutes the original classification is the previous technique of dissection of the specimens. Specimens of the lower urinary tract were opened by a midline anterior approach, leaving the posterior wall intact, splitting the membrane obstruction, giving an impression of a valvular obstruction between two paramedian reinforcements. Jarjavay, in 1856, was the first to give an illustration of a diaphragm that was again highlighted by Lederer in 1911, both papers being quoted by Young et al., in 1919 .
Young's also gave insight into urological disease in boys when he raised the question of variability of obstruction of the posterior urethra. He and his co-authors wrote, "It should be borne in mind that varying degrees of congenital obstruction may exist, which may result in symptoms so slight that the condition is unrecognised" (page 297). In contrast, there was little clue to the modern concept of the interrelationship of the external sphincter and the obstructing tissue in the presentation in 1919.

Despite the poor radiological images, primitive endoscopic equipment limited clinical understanding of obstructive uropathy and little access to information technology, through careful observation and the pursuit of knowledge through the literature, Hugh Hampton Young and his team created a landmark paper. As the reader will see, our understanding of the anatomy and clinical course for boys with urethral obstruction has been significantly enhanced by Young's work.

To better understand the conclusions reached on interpretation of the anatomy of posterior urethral obstruction it is necessary to discuss bulbar urethral narrowing.

Type III valves are rare inframontane, bulbar urethral lesions with a central rather than posterior defect - if you take the consensus. Cobb et al. were the first to describe a significant number of cases of narrowing in the bulbar urethra which appeared to be congenital; hence the term Cobb's collar ${ }^{21}$. They suggested that minor changes could often be seen if the urethra was entered under direct vision. However, the understanding of Cobb's collar appears to have been confused by studies grouping boys with older men; studies of urethrograms without cystoscopy; confusion between prolapsed lesions of the posterior urethra and those which are of the bulbar urethra primarily; and regarding all bulbar constrictions as pathological rather than some as merely anatomical variations ${ }^{22-29}$. Moormann's ring is another term used for a congenital narrowing in the bulbar urethra. The presence of two separate terms may have added to the confusion.

Cobb thought the lesion could not be muscle, as the 26 children he recorded had a narrowing which was not affected by succinylcholine ${ }^{21}$. Moormann's patients ranged from 21 to 54 years in age ${ }^{22}$. These constricting bulbar urethral lesions in older men may be spasm of intrinsic urethral muscle or spasm of the bulbospongiosus, highlighting that the bulbar urethral findings may be either muscular or membranous, and the delayed presentation of adults suggests that the narrowing is most likely to be muscular in the older patients. Currarino showed a Cobb's Collar impression on radiographs, with variable appearance between patients concluding that the radiological findings were due to contraction of periurethral muscle, which we also identified in 21 boys $^{26,7}$. 
The embryonic origin of Cobb's Collar seems to be the result of the persistence of the urogenital membrane, which can be minor or significant, muscular or fibrous. Congenital obstruction of the bulbar urethra has not often been discussed in the literature, possible because many would agree with Cobb's observation in $1968^{21}$, that insertion of the cystoscope, whilst visualizing the urethra, will often show the presence of a ring narrowing of the bulbar urethra, and therefore it is not worthy of recording; a conclusion also reached by Cranston et $\mathrm{al}^{29}$. Significant pathology does occur, however, which has been classified according to the degree of encroachment on the lumen (mild, moderate and severe) and the presence of muscle or a fibrous membrane within the narrowed segment ${ }^{30}$.

The incidence of obstructive Cobb's Collar is certainly very low in the general community and only $78 \%$ who have endoscopic evidence of a narrowing also had abnormality detected on cystogram, indicating that a minor indentation is a normal, common variant ${ }^{7}$.

Bladder and renal function management are the most important considerations in the management of an infant who has significant upper tract changes. There are numerous publications debating the pro's and con's of various interventions, probably each case is very individual and should be managed with all the armamentarium available, depending on the specific initial findings and the responses to treatment. A fatalistic approach to the outcome for renal function should not be adopted.

\section{DISCLOSURE}

The author declared no competing interest.

\section{References}

1. Imaji R, Moon DA, Dewan PA. Congenital posterior urethral membrane: Variable morphological expression. J Urol 2001; 165: 1240-3.

2. Imaji R, Dewan PA. The clinical and radiological findings in boys with endoscopically severe congenital posterior urethral obstruction. BJU Int 2001; 88: 263-7.

3. Dewan PA, Pillay S, Kaye K. Correlation of the endoscopic and radiological anatomy of congenital obstruction of the posterior urethra and the external sphincter. Br J Urol 1997; 79: 790-6.

4. Dewan PA, Goh DG. Variable expression of the congenital obstructive posterior urethral membrane. Urol 1995; 45(3): 507-9.

5. Dewan PA. Congenital obstructing posterior urethral membrane (COPUM): further evidence for a common morphological diagnosis. Pediatr Surg Int 1993; 8: 45-50.

6. Dewan PA, Keenan RJ, Lequesne GW, Morris LL. Congenital bulbar urethral obstruction: Cobb's collar or prolapsed COPUM. Br J Urol 1994; 73: 91-96.

7. Dewan PA, Goh DG, Crameri J. Cobb's collar. Paediatr Surg Int 1995: 10: 243-6.

8. Lu Y, Dewan PA. Congenital obstructive posterior urethral membrane: the video endoscopic perspective. Br.J. Urol. International, 2006; 98: 953-959.
9. Morgagni JB. Seats and causes of diseases investigated by anatomy; in five books, containing a great variety of dissections with remarks to which are added very accurate and copious indexes of the principal things and names therein contained. 1769;3:540.

10. Langenbeck JM. Eine einfache und sichere methode des steinschnittes. 1802.

11. Velpeau AALM. Urètre et Prostate. Traite Complet d'anatomie Chirurgicale. 1832; 2: 247.

12. Budd G. Case of extraordinary dilatation of the kidneys, ureters, and bladder, in consequence of a membranous fold in the urethra, which acted as a valve, and prevented free escape of the urine from the bladder. Lancet. 1840; 1: 767.

13. Bednar A. Beitrag zur ischuria neonatorum. Zischr d K K Gesellsch der Aerzte zu Wien. 1847; 2: 279.

14. Godart A. Valvule anormale dans le canal de l'urèthre. Bull Soc Anat de Paris 1854; 24: 137.

15. Jarjavay JF. Recherches anatomiques sur l'urèthre de l'homme. Paris. 1856; 28.

16. Lederer R. Uber eine angeborene membranose Verengung der pars prostatica urethrae. Arch Pathol Anat 1911; 203: 240-6.

17. Lowsley OS. Congenital malformations of the posterior urethra. Ann Surg: 1914;60: 733-41.

18. Pugh MB. Stedman's Medical Dictionary, $27^{\text {th }}$ edn. Baltimore: Lippincott Williams and Wilkins, 2000; 1927-8.

19. Young HH, Frontz WA, and Baldwin JC. Congenital obstruction of the posterior urethra. J Urol 1919; 3: 289

20. Young HH, McKay RW. Congenital valvular obstruction of the posterior urethra. Surg Gynecol \& Obstet 1929; 48: 509.

21. Cobb BG, Wolf JA, Ansell JS. Congenital stricture of the proximal urethral bulb. J Urol 1968; 99: 629-31.

22. Moormann JG. Congenital bulbar urethral stenosis as a cause of disease of the urogenital junction. Urologe 1972; 11:157-60.

23. English PJ, Pryor JP. Congenital bulbar urethral stricture occurring in a father and son. Br J Urol 1986; 58: 732.

24. Jones DJ. Congenital bulbar urethral stricture occurring in two brothers. Urol Int 1988; 43: 366-7.

25. Rao KG. Congenital proximal bulbar stricture in adult urology. Urol 1975; 6: 576-9.

26. Currarino G. Narrowings of the male urethra caused by contractions or spasm of the bulbocavernosis muscle: cystourethrographic observations. A J R 1970; 108: 641-647.

27. Currarino G, Stephens FD. An uncommon type of bulbar urethral stricture, sometimes familial, of unknown cause: congenital versus acquired. J Urol 1981; 126: 658-62.

28. Gaisie G, Mandell J, Scatliff JH. Congenital stenosis of the male urethra. A J R 1984; 142: 1269-71.

29. Cranston D, Davies AH, Smith JC. Cobb's collar - a forgotten entity. Br J Urol 1990; 66: 294-6.

30. Dewan PA, Goh DG, Crameri J. Cobb's collar. Paediatr Surg Int 1995; 10: 243-6. 